OPEN ACCESS

Edited by:

Daniel Olive,

Aix Marseille Université, France

Reviewed by:

Elke Pogge Von Strandmann

University of Marburg, Germany

Margherita Doria,

Bambino Gesù Children Hospital

(IRCCS), Italy

${ }^{*}$ Correspondence:

Rossella Paolini

rossella.paolini@uniroma1.it

Specialty section:

This article was submitted to

Cancer Immunity and Immunotherapy,

a section of the journal

Frontiers in Immunology

Received: 24 July 2019 Accepted: 15 October 2019 Published: 31 October 2019

Citation:

Molfetta $R$, Zingoni A, Santoni $A$ and

Paolini R (2019) Post-translational

Mechanisms Regulating NK Cell

Activating Receptors and Their

Ligands in Cancer: Potential Targets

for Therapeutic Intervention.

Front. Immunol. 10:2557.

doi: 10.3389/fimmu.2019.02557

\section{Post-translational Mechanisms Regulating NK Cell Activating Receptors and Their Ligands in Cancer: Potential Targets for Therapeutic Intervention}

\author{
Rosa Molfetta, Alessandra Zingoni, Angela Santoni and Rossella Paolini*
}

Department of Molecular Medicine, Sapienza University of Rome, Laboratory Affiliated to Istituto Pasteur Italia-Fondazione Cenci Bolognetti, Rome, Italy

Efficient clearance of transformed cells by Natural Killer (NK) cells is regulated by several activating receptors, including NKG2D, NCRs, and DNAM-1. Expression of these receptors as well as their specific "induced self" ligands is finely regulated during malignant transformation through the integration of different mechanisms acting on transcriptional, post-transcriptional, and post-translational levels. Among post-translational mechanisms, the release of activating ligands in the extracellular milieu through protease-mediated cleavage or by extracellular vesicle secretion represents some relevant cancer immune escape processes. Moreover, covalent modifications including ubiquitination and SUMOylation also contribute to negative regulation of NKG2D and DNAM-1 ligand surface expression resulting either in ligand intracellular retention and/or ligand degradation. All these mechanisms greatly impact on NK cell mediated recognition and killing of cancer cells and may be targeted to potentiate NK cell surveillance against tumors. Our mini review summarizes the main post-translational mechanisms regulating the expression of activating receptors and their ligands with particular emphasis on the contribution of ligand shedding and of ubiquitin and ubiquitin-like modifications in reducing target cell susceptibility to NK cell-mediated killing. Strategies aimed at inhibiting shedding of activating ligands and their modifications in order to preserve ligand expression on cancer cells will be also discussed.

Keywords: activating NK cell receptors, ligands for NK cell activating receptors, post-translational modifications, shedding, ubiquitin modification

\section{INTRODUCTION}

Natural Killer (NK) cell activation is tuned by the integration of signals derived from inhibitory receptors for Major Histocompatibility Complex (MHC) class I molecules and from activating receptors that bind either non self-molecules associated to pathogens or self-molecules up-regulated in stress conditions including malignant transformation $(1,2)$.

Among activating receptors, Natural-Killer receptor group 2, member D (NKG2D), DNAX-associated molecule1 (DNAM-1), and the Natural Cytotoxicity Receptors (NCRs) play a pivotal role in NK cell-mediated tumor surveillance as revealed by an increased incidence of spontaneous malignancies or impaired tumor clearance 
in mice deficient for these receptors (3-7). In human, NCR expression may represent a prognostic biomarker in acute myeloid leukemia (AML) and solid tumors (8-10). Moreover, the engagement of the low affinity receptor for IgG (CD16) by means of natural or therapeutic monoclonal antibodies can also contribute to tumor clearance through antibody-dependent cellular cytotoxicity (ADCC) $(11,12)$.

\section{NK Cell Activating Receptors and Their Ligands on Tumor Cells}

NKG2D is a C-type lectin receptor not exclusively expressed on NK cells but also found on NKT, CD ${ }^{+} \alpha \beta \mathrm{T}$ cells, $\gamma \delta$ $\mathrm{T}$ cells, and activated $\mathrm{CD}^{+} \alpha \beta \mathrm{T}$ cells (13-15). In humans, NKG2D binds to the adaptor DNAX activating protein 10 (DAP10), responsible for signal propagation. In murine activated NK cells, a shorter NKG2D isoform can either associate with DAP10 or DAP12, an alternative signal transducing adaptor $(16,17)$.

Human NKG2D ligands (NKG2DLs) belong to two families of polymorphic molecules structurally related to MHC class I: the MHC class I related proteins (MIC)A/B which possess $\alpha 1$, $\alpha 2$, and $\alpha 3$ domains similar to MHC molecules and six UL16 binding proteins (ULBP1-6) characterized by $\alpha 1$ and $\alpha 2$ domains $(15,18,19)$. MICA and MICB are generally transmembrane proteins, while ULBP proteins can be transmembrane (ULBP4 and 6) or GPI-linked (ULPB1-3 and 5) molecules. Murine NKG2DLs include Rae- $1 \alpha-\varepsilon$, MULT1, and H60a-c and are expressed either as transmembrane or GPI-linked molecules (18).

DNAM-1 belongs to the immunoglobulin receptor family and is expressed not only on NK cells but also on monocytes, T cells, and subsets of B cells $(14,20,21)$. It binds to Nectin2/CD112 and PVR/CD155 both members of the Nectin/Nectin-like family of adhesion molecules (22-24), and it associates with the integrin LFA1 to transduce intracellular signals.

Natural cytotoxicity receptors comprise NKp46, NKp44, and NKp30 immunoglobulin-like receptors that are not exclusively expressed on NK cells but also on innate lymphoid cells (ILCs) of group 1 (ILC1) and a subset of ILC3, $\gamma \delta$ T cells, and a population of cytotoxic T lymphocytes $(25,26)$. Only ortholog of NKp46 is expressed in mice (26).

NKp30 and NKp46 associate with the signal transducing adaptors $\mathrm{CD} 3 \zeta$ and FceRI $\gamma$ while NKp44 mainly signals through the DAP12 adapter. Splicing variants of NKp44 and NKp30 endowed with inhibitory signal capability have been described and are associated with worst prognosis in cancer patients $(9,27)$.

NCRs interact with several ligands that are either pathogenencoded or self-molecules and include cell surface and intracellular proteins that reach the surface in infected or transformed cells (28). However, the ligands expressed on tumor cells have not been fully identified yet.

Each NCR has the ability to recognize a specific configuration of heparan sulfate proteoglycans expressed in the context of tumor microenvironment, and this binding can modulate receptor function (28).
Ligands for NKp30 include B7-H6 belonging to the B7 family and only expressed on tumor cells, the intracellular protein HLAB associated transcript 3 (BAT3), also known as BAG6, and galectin-3 (29-31). The first two ligands bind to and activate NKp30 while the released form of galectin-3 inhibits anti-tumor NKp30 function.

NKp44 interacts with the Proliferating Cell Nuclear Antigen (PCNA), which is aberrantly expressed on the surface of tumor cells. This binding preferentially engages an inhibitory isoform of NKp44 and negatively regulates NK cell functions (32). Interaction between NKp44 and a subset of HLA-DP molecules has been recently reported (33) demonstrating that HLA class II molecules may impact on NK cell activity. Of note, NKp44 can be triggered by specific tumor-derived soluble growth factors (34) and by Nidogen-1, an extracellular matrix protein (35). NKp46 recognize viral ligands including hemagglutinins as well as tumor ligands of still unknown identity.

Most of the above mentioned NK cell activating ligands, including NKG2DLs and B7-H6, are absent in normal cells but their expression is induced upon neoplastic transformation, thus rendering tumor cells more susceptible to NK cell-mediated killing (29, 36-41).

On the other hand, PVR and Nectin2 are expressed on healthy cells (21) but their amount is up-regulated on epithelial and hematological tumor cells promoting NK cell cytotoxicity $(7,42-44)$.

\section{POST-TRANSLATIONAL MECHANISMS MODULATING MEMBRANE EXPRESSION OF NK CELL ACTIVATING LIGANDS ON TUMOR CELLS}

During malignant transformation different stressful stimuli are responsible for the induction of NK cell activating ligands at transcriptional and post-transcriptional levels and the molecular mechanisms implicated have been partially identified (18, 45). Moreover, increasing evidence demonstrate that posttranslational mechanisms including the release of ligands for NK cell activating receptors as soluble forms as well as ligand modification by the Ubiquitin (Ub) or Ub-like pathways are used by tumor cells to dampen activating ligand surface expression in order to evade NK cell recognition (Figure 1A).

\section{Mechanisms Implicated in the Release of Ligands for NK Cell Activating Receptors}

Most of the information regarding soluble ligands in cancer patients comes from studies performed on NKG2DLs. These molecules are present in the sera of patients affected by hematological or solid malignancies, and their level correlate with tumor stage and poor prognosis (46-53). More recently, B7-H6, BAG6, and PVR soluble forms have been found in the sera of patients affected by different type of tumors suggesting a relationship between soluble ligand expression and cancer progression (54-58).

Generation of soluble ligands relies on different mechanisms including alternative splicing, exosome secretion and proteolytic 


\section{A}

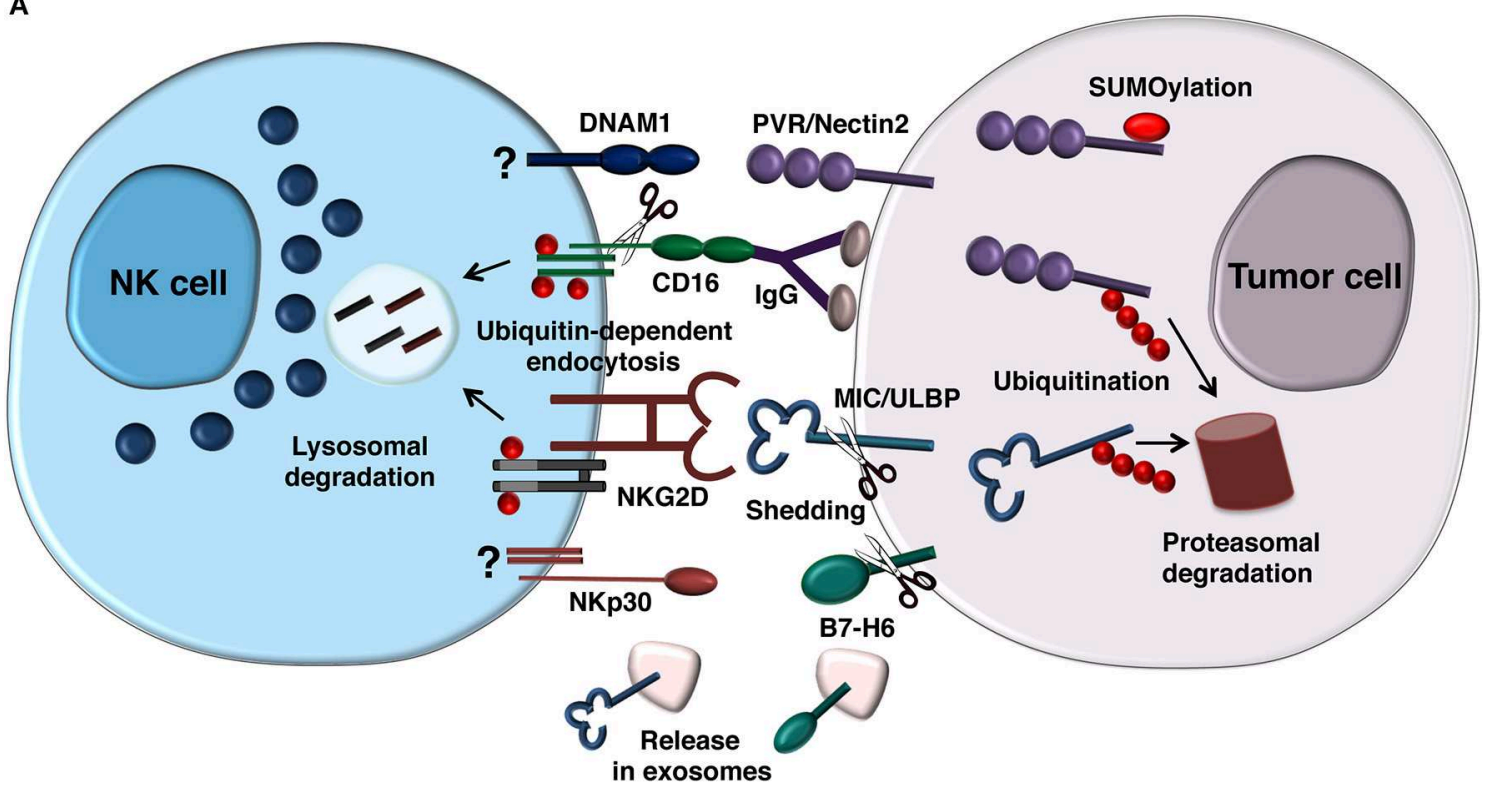

B
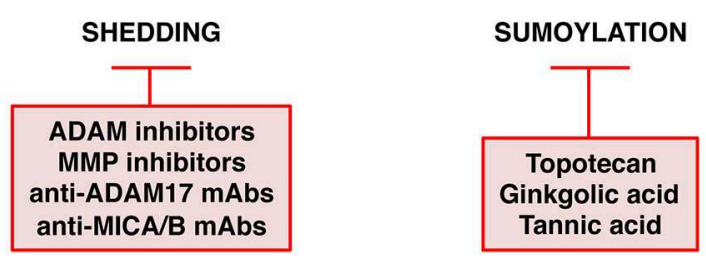

PROTEASOMAL DEGRADATION

FIGURE 1 | Post-translational mechanisms controlling NK cell-mediated recognition of tumor cells. (A) Model depicting how NCR (B7-H6), NKG2D, and DNAM1 ligand expression is prevented by post-translational mechanisms on target cell surface (right). Release of B7-H6 and NKG2D ligands on exosomes is also depicted. In addition to regulate ligand expression on tumor cell, ubiquitin modification also provides a signal for internalization and trafficking of NKG2D and CD16 on NK cells (left). CD16 is also downmodulated by metalloproteinase-mediated shedding. Mechanisms regulating DNAM-1 and NCR (NKp30) downmodulation are currently unknown. (B) Therapeutic strategies aimed to prevent post-translational mechanisms affecting activating ligand and receptor expression.

cleavage. Soluble PVR isoforms are generated by alternative splicing (59) and have an inhibitory effect on DNAM-1 mediated tumor immunity (54). In addition, alternative splicing gives rise to ULBP-4/5 secreted ligands that can impair NK cell target recognition in vitro $(60,61)$.

Exosomes represents nanovesicles derived from the endosomal compartment (62) and have been involved in the secretion of NKG2D and NKp30 ligands but not of DNAM-1 ligands (63). Differently from the proteolytic-mediated release, expression of activating ligands on the exosome surface should retain their biological activity by keeping the integral-molecule. A number of studies have shown that NKG2DLs from both MIC and ULBP families are expressed on the surface of exosome-like vesicles released from ovarian cancer (63), melanoma (64), and prostate cancer cells (65). Remarkably, NKG2DLs such as ULBP3 and ULBP1 $(66)$ or the allelic variant $\operatorname{MICA}^{*} 008(67,68)$ that are glycosylphosphatidylinositol (GPI)-anchored proteins, are preferentially released via exosomes.

In regard to NKp30Ls, the nuclear protein BAG6 is secreted on exosomes and stimulates NK cell activity (69), whereas the cell surface ligand B7-H6 can be released in its soluble form associated to exosomes or through protease-mediated cleavage (57, 70, 71). Although several stress conditions can increase exosome secretion from cancer cells (72-75), it is still uncertain whether the release of NKG2DLs or B7-H6 through exosome-like vesicles could result in the diminution of their expression on the cell surface.

Concerning the shedding process, MICA, MICB, and ULBP2 are cut by metalloproteinases belonging to two distinct families, the matrix metalloproteinases (MMPs) and a disintegrin and metalloproteinases (ADAMs) (76-81), whereas the B7H6 proteolytic cleavage occurs through a mechanism mainly dependent on ADAM enzymes (57). A recent study has shown that some ULBP4 isoforms are sensitive to the protease cleavage (82). Both MMPs and ADAMs proteases undergo modulation of their activity and expression in the course of neoplastic transformation $(83,84)$ and in response to cancer therapy $(85-$ 88). Disparate sensitivity to the proteases has been described for distinct NKG2DLs and/or allelic variants and isoforms. For instance, the generation of soluble MICA can be affected by 
polymorphisms as shown for the MICA*008 allele that is resistant to the protease-mediated cleavage. Moreover, the MICA-129 dimorphism, producing a valine to methionine swap at position 129 , influenced the MICA cleavage process but the mechanism behind has to be defined $(89,90)$. In addition, proteolytic cleavage can be affected by fatty acylation and palmytolation that mediate MICA/B recruitment to membrane microdomains $(78,91)$.

Differently from the exosome-mediated release, the proteolytic cleavage of NKG2DLs and B7H6 has been associated to a reduction of cell surface ligands, thus its inhibition could be accomplished as a promising approach to keep the ligands on cancer cell surface and to promote anti-cancer immune response.

\section{Activating Ligand Modification by $\mathrm{Ub}$ and Ub-Like Pathways}

Recent evidences reveal a role for ubiquitination and SUMOylation in the regulation of NK cell ligand expression on tumor cells.

Ubiquitination and SUMOylation are reversible modifications whereby Ub and small Ub-like modifier (SUMO), respectively, are covalently bound to a target protein through the action of enzymes frequently up-regulated during malignant transformation (92-95).

Once modified, proteins undergo different fate depending on the type of modification.

Proteins modified by poli-Ub chains are generally targeted to proteasomal degradation (95) whereas the addition of single Ub molecules to one or more lysine residues promote non-degradative fates including regulation of membrane protein endocytosis (96). SUMOylated substrates undergo conformational changes that in turn modify their interaction with other proteins or their enzymatic activity without inducing a degradative fate (94).

Little is currently known about the role of these modifications in the regulation of $\mathrm{NK}$ cell ligand expression during malignant transformation.

Ubiquitination of MICA/B has been demonstrated in Kaposi's sarcoma-associated herpesvirus infected cells: the viral E3 Ub ligase K5 induces modification of both NKG2DLs and their intracellular retention (97). Moreover, in healthy cells the murine ULBP-1 ortholog MULT-1 undergoes constitutive ubiquitination and lysosomal degradation $(98,99)$. Interestingly, stress conditions including UV radiation and heat shock prevent MULT-1 ubiquitination and increase its surface expression (98). Thus, these results support a negative role for the Ub pathway in the regulation of NKG2DL expression.

In tumor cells a direct implication of the $\mathrm{Ub}$ pathway has not been formally reported but several data demonstrate that surface expression of human NKG2DLs is regulated by a rapid protein turnover. In melanoma cells, an immature form of MICA accumulates in the endoplasmic reticulum and is targeted to degradation (100). MICB is internalized and retained intracellularly in several tumor cell lines (101), while in Multiple Myeloma (MM) cells the constitutive internalization of MICB is followed by its lysosomal degradation (102). Similarly, the GPI-linked ligand ULBP1 is continuously removed from plasma membrane and targeted to proteasomal degradation (103). Regarding DNAM-1 ligands, in hepatocellular carcinoma the activation of Unfolded Protein Response (UPR) inhibits PVR surface expression and promotes protein degradation (104). In line with this result, ubiquitination and SUMOylation negatively regulates surface expression of Nectin2 and PVR on tumor cells $(105,106)$. Ubiquitinated Nectin2 is retained in intracellular compartments but also targeted to proteasomal degradation (106) whereas SUMOylation of PVR promotes its intracellular retention without inducing protein degradation (105). Inhibition of Ub and SUMO pathways increases Nectin2 and PVR surface expression and renders tumor cells more sensitive to NK cellmediated killing.

Although these findings are currently limited to NKG2D and DNAM-1 ligands, they provide novel insights into the mechanisms underlying activating ligand expression in diseased cells and reveal novel potential targets for therapeutic intervention.

\section{LIGAND INDUCED DOWN-MODULATION OF NK CELL ACTIVATING RECEPTOR EXPRESSION}

Tumor progression also implies the inability of NK cells to kill tumor cells as consequence of ligand mediated down-regulation of activating receptors (Figure 1A).

However, receptor down-regulation may be affected by the presence of soluble or membrane-bound ligands as well as by their affinity and/or avidity (19).

A decreased in NCR expression levels was observed in NK cells derived from patients affected by myeloid leukemia and other tumors upon the interaction with their respective ligands $(8,107)$.

Reduced NKp30 surface expression has been also detected on NK cells derived from ovarian carcinoma and neuroblastoma patients as a result of chronic stimulation either with B7-H6expressing tumor cells or soluble B7-H6 $(55,56,108)$. Moreover, the presence of soluble BAG6 has been associated with a low transcriptional levels of different NKp30 isoforms $(58,109)$.

DNAM-1 engagement, by membrane-bound ligands but not their soluble counterpart, is also followed by receptor downmodulation and impairment of NK cell functions in patients affected by different tumors including MM, ovarian carcinoma and AML (44, 110, 111). However, the mechanisms underlying these effects are still undefined.

For other activating receptors including NKG2D and CD16, mechanisms of ligand-induced down-modulation have been elucidated.

NKG2D stimulation by ligands expressed on tumor cells as well as by soluble ligands promotes receptor endocytosis and the decrease of NKG2D-dependent functions (46, 76, 112-115). In regard to released ligands, those associated to exosomes show a higher avidity and a more efficient ability to induce receptor down-regulation compared to shed ligands $(66,67)$.

In humans, internalization of ligand-engaged NKG2D receptors requires DAP10 ubiquitination and is followed by 
lysosomal degradation (116). However, MICA is more efficient than ULBP2 in promoting receptor ubiquitination (114).

Ub modification has been also implicated in the downmodulation of CD16 in response to antibody-coated tumor cells (117-119). Indeed, CD16 clearance from NK cell surface is mainly induced by Ub-dependent endocytosis of aggregated receptors followed by degradation of CD16 $\zeta$ subunit and the associated kinases $(114,117,120)$. However, CD16 down-regulation can also occur as a consequence of metalloproteinase-induced receptor shedding (121-124). Regardless, NK cell-mediated ADCC, natural cytotoxicity, and the efficacy of antibody-based therapies resulted impaired $(118,119,125)$.

Altogether these results demonstrate that activating receptor expression is modulated in tumor microenvironment by the interaction with ligand-expressing cells, thus impairing NK cell ability to counteract tumor development.

\section{TARGETING POST-TRANSLATIONAL MECHANISMS REGULATING NK CELL-MEDIATED RECOGNITION AND KILLING OF CANCER CELLS}

All these post-translational mechanisms represent potential targets for therapeutic intervention (Figure 1B). Ligand shedding blocking can be achieved by the usage of inhibitors of MMPs and ADAMs enzymes (57, 77, 126). Since ADAM10 and ADAM17 sheddases play a prominent role in B7-H6 (57) and NKG2DL cleavage $(77,78,80,127)$, the selective targeting of such enzymes might be promising for anticancer therapy. Recently, by performing an in vitro drug screen using an FDA-approved drug library, lomofungin was found to strongly decrease ADAM17 activity in hepatocellular carcinoma leading to the impairment of MICA shedding and has been proposed as new drug candidate for immunotherapy in liver cancer (128). Most of the compounds able to inhibit ADAM catalytic activity are hydroxamate-based and are either selective for ADAM17 or inhibitors of both ADAM10 and ADAM17 (129). Of interest, the synthesis of new selective ADAM10 inhibitors able to impair NKG2DL shedding in Hodgkin's lymphoma cell models has been reported (130). ADAM10 and ADAM17 are expressed at high levels on the surface of glioblastoma-initiating cells thus contributing to an immunosuppressive phenotype through the ULBP2 cleavage. Specific inhibition of these enzymes preserved cell surface ULBP2 leading to increased glioblastoma cell recognition and killing by NK cells (131). Remarkably, in vivo experiments using athymic nu-/nu- mice implanted with subcutaneous HeLa tumors demonstrated that systemic MMPi treatment resulted in the reduction of MICA serum levels and a concomitant augmentation of MICA expression on cancer cells reinforcing the immune cell therapy mediated by cytokine-induced killer cells (132). Of interest, adoptively transferred NK cells displaying high levels of surface NKG2D determined the clearance of soluble MICA in neuroblastoma patients by preserving NK cell cytotoxicity via non-occupied NKG2D (133).
Another appealing strategy to specifically inhibit MICA/B proteolytic cleavage concerns the generation of antibodies targeting the MIC protein domain involved in the proteolytic cleavage (134). Interestingly the usage of these antibodies limited MICA/B shedding in human cancer cells and repressed cancer cell growth in in vivo models (134). More recently, the glycosylation-engineered epitope mapping (GEM) method allowed to the identification of a number of epitopes relevant for MICA/B shedding inhibition (135).

In general, such antibodies as well as metalloproteinase inhibitors could be used in combination with other therapies aimed at the enhancement of ligand expression on the surface of cancer cells including DNA damaging agents (127), radiations (87), and chemotherapeutic drugs (132). Our group has shown that the combined use of metalloproteinase inhibitors and genotoxic drugs enhanced NK cell-mediated killing of multiple myeloma cells by preserving MIC molecules on the cell surface (127). To date, ADAMs inhibitors have been largely unsuccessful in clinical trials, but they remain a viable and desirable therapeutic target based on preclinical studies.

Strategies aimed at inhibiting ADAM17-mediated CD16 cleavage from the surface of NK cells could be also promising. Beyond the usage of inhibitors, recent advances in generating function-blocking antibodies of ADAM17 are emerging. The monoclonal antibody MEDI3622 has been shown to block CD16A cleavage from activated human NK cells allowing to an increased IFN $\gamma$ production in the course of ADCC (136).

Proteasome inhibitors can change the fate of ubiquitinated ligands. Bortezomib (Velcade) and Carfilzomib (Kyprolis) have been already used as chemotherapeutic drugs for relapsed MM patients (137-139) and for the treatment of mantle cell lymphoma (140).

In line with our findings (106), previous reports demonstrated that low doses of bortezomib increase NK cell activating ligand, including Nectin2 (141-143). Whether those drugs can directly affect ligand expression stabilizing ubiquitinated Nectin2 and/or SUMOylated PVR is currently unknown.

Regarding the SUMO pathway, the FDA-approved drug Topotecan has been shown to affect SUMOylation in glioblastoma multiforme (144). Moreover, natural compounds including ginkgolic acid and tannic acid $(145,146)$ have been found to possess anti-cancer activities by targeting the SUMO pathway (147).

All of these compounds hold great promise to be developed into novel and efficient anti-cancer drugs.

\section{CONCLUSION AND THERAPEUTIC PERSPECTIVES}

On tumor cells, several activating ligands are subjected to protease-mediated cleavage with a consequent dramatic reduction of their surface expression. A similar effect is also achieved upon ubiquitination or SUMOylation of NKG2D and DNAM-1 ligands, which are retained intracellularly and/or degraded. 
On NK cells, the Ub pathway may also contribute to downregulate the surface expression of activating receptors.

In conclusion, all these post-translational mechanisms act to reduce NK cell-mediated surveillance against tumors and represent potential targets for therapeutic intervention.

Several inhibitors have been developed and their use in combination with conventional therapies represent a useful tool to potentiate NK-cell mediated recognition and killing of tumor cells.

\section{REFERENCES}

1. Long EO, Kim HS, Liu D, Peterson ME, Rajagopalan S. Controlling natural killer cell responses: integration of signals for activation and inhibition. Ann Rev Immunol. (2013) 31:227-58. doi: 10.1146/annurev-immunol-020711-075005

2. Morvan MG, Lanier LL. NK cells and cancer: you can teach innate cells new tricks. Nat Rev Cancer. (2016) 16:7-19. doi: 10.1038/nrc.2015.5

3. Guerra N, Tan YX, Joncker NT, Choy A, Gallardo F, Xiong N, et al. NKG2D-deficient mice are defective in tumor surveillance in models of spontaneous malignancy. Immunity. (2008) 28:571-80. doi: 10.1016/j.immuni.2008.02.016

4. Iguchi-Manaka A, Kai H, Yamashita Y, Shibata K, Tahara-Hanaoka S, Honda $\mathrm{S}$, et al. Accelerated tumor growth in mice deficient in DNAM-1 receptor. $J$ Exp Med. (2008) 205:2959-64. doi: 10.1084/jem.20081611

5. Gilfillan S, Chan CJ, Cella M, Haynes NM, Rapaport AS, Boles KS, et al. DNAM-1 promotes activation of cytotoxic lymphocytes by nonprofessional antigen-presenting cells and tumors. J Exp Med. (2008) 205:296573. doi: $10.1084 /$ jem.20081752

6. Halfteck GG, Elboim M, Gur C, Achdout H, Ghadially H, Mandelboim O. Enhanced in vivo growth of lymphoma tumors in the absence of the NK-activating receptor NKp46/NCR1. J Immunol. (2009) 182:222130. doi: 10.4049/jimmunol.0801878

7. Lakshmikanth T, Burke S, Ali TH, Kimpfler S, Ursini F, Ruggeri L, et al. NCRs and DNAM-1 mediate NK cell recognition and lysis of human and mouse melanoma cell lines in vitro and in vivo. J Clin Invest. (2009) 119:125163. doi: 10.1172/JCI36022

8. Fauriat C, Just-Landi S, Mallet F, Arnoulet C, Sainty D, Olive D, et al. Deficient expression of NCR in NK cells from acute myeloid leukemia: evolution during leukemia treatment and impact of leukemia cells in NCRdull phenotype induction. Blood. (2007) 109:323-30. doi: 10.1182/blood-2005-08-027979

9. Delahaye NF, Rusakiewicz S, Martins I, Menard C, Roux S, Lyonnet L, et al. Alternatively spliced NKp30 isoforms affect the prognosis of gastrointestinal stromal tumors. Nat Med. (2011) 17:700-7. doi: 10.1038/nm.2366

10. Chretien AS, Fauriat C, Orlanducci F, Rey J, Borg GB, Gautherot E, et al. NKp30 expression is a prognostic immune biomarker for stratification of patients with intermediate-risk acute myeloid leukemia. Oncotarget. (2017) 8:49548-63. doi: 10.18632/oncotarget.17747

11. Mentlik James A, Cohen AD, Campbell KS. Combination immune therapies to enhance anti-tumor responses by NK cells. Front Immunol. (2013) 4:481. doi: 10.3389/fimmu.2013.00481

12. Battella S, Cox MC, Santoni A, Palmieri G. Natural killer (NK) cells and antitumor therapeutic mAb: unexplored interactions. J Leukocyte Biol. (2016) 99:87-96. doi: 10.1189/jlb.5VMR0415-141R

13. Ullrich E, Koch J, Cerwenka A, Steinle A. New prospects on the NKG2D/NKG2DL system for oncology. Oncoimmunology. (2013) 2:e26097. doi: 10.4161/onci.26097

14. Marcus A, Gowen BG, Thompson TW, Iannello A, Ardolino M, Deng $W$, et al. Recognition of tumors by the innate immune system and natural killer cells. Adv Immunol. (2014) 122:91-128. doi: 10.1016/B978-0-12-800267-4.00003-1

\section{AUTHOR CONTRIBUTIONS}

$\mathrm{RM}, \mathrm{AZ}, \mathrm{AS}$, and RP participated in the conception, writing, and elaboration of the final version of the manuscript.

\section{FUNDING}

This work was supported by grants of Italian Association for Cancer Research (AIRC Investigator Grant cod. 16014 and AIRC 5x1000) and Sapienza University (RM1181642771A58E).

15. Lanier LL. NKG2D receptor and its ligands in host defense. Cancer Immunol Res. (2015) 3:575-82. doi: 10.1158/2326-6066.CIR-15-0098

16. Diefenbach A, Tomasello E, Lucas M, Jamieson AM, Hsia JK, Vivier E, et al. Selective associations with signaling proteins determine stimulatory versus costimulatory activity of NKG2D. Nat Immunol. (2002) 3:11429. doi: $10.1038 /$ ni858

17. Gilfillan S, Ho EL, Cella M, Yokoyama WM, Colonna M. NKG2D recruits two distinct adapters to trigger NK cell activation and costimulation. Nat Immunol. (2002) 3:1150-5. doi: 10.1038/ni857

18. Raulet DH, Gasser S, Gowen BG, Deng W, Jung H. Regulation of ligands for the NKG2D activating receptor. Ann Rev Immunol. (2013) 31:41341. doi: 10.1146/annurev-immunol-032712-095951

19. Zingoni A, Molfetta R, Fionda C, Soriani A, Paolini R, Cippitelli M, et al. NKG2D and its ligands: "one for all, all for one". Front Immunol. (2018) 9:476. doi: 10.3389/fimmu.2018.00476

20. Shibuya A, Campbell D, Hannum C, Yssel H, Franz-Bacon K, McClanahan T, et al. DNAM-1, a novel adhesion molecule involved in the cytolytic function of $\mathrm{T}$ lymphocytes. Immunity. (1996) 4:573-81. doi: 10.1016/S1074-7613(00)70060-4

21. de Andrade LF, Smyth MJ, Martinet L. DNAM-1 control of natural killer cells functions through nectin and nectin-like proteins. Immunol Cell Biol. (2014) 92:237-44. doi: 10.1038/icb.2013.95

22. Bottino C, Castriconi R, Pende D, Rivera P, Nanni M, Carnemolla B, et al. Identification of PVR (CD155) and Nectin-2 (CD112) as cell surface ligands for the human DNAM-1 (CD226) activating molecule. J Exp Med. (2003) 198:557-67. doi: 10.1084/jem.20030788

23. Tahara-Hanaoka S, Shibuya K, Onoda Y, Zhang H, Yamazaki S, Miyamoto A, et al. Functional characterization of DNAM-1 (CD226) interaction with its ligands PVR (CD155) and nectin-2 (PRR-2/CD112). Int Immunol. (2004) 16:533-8. doi: 10.1093/intimm/dxh059

24. Chan CJ, Smyth MJ, Martinet L. Molecular mechanisms of natural killer cell activation in response to cellular stress. Cell Death Different. (2014) 21:5-14. doi: 10.1038/cdd.2013.26

25. Moretta A, Bottino C, Vitale M, Pende D, Cantoni C, Mingari $\mathrm{MC}$, et al. Activating receptors and coreceptors involved in human natural killer cell-mediated cytolysis. Ann Rev Immunol. (2001) 19:197223. doi: 10.1146/annurev.immunol.19.1.197

26. Barrow AD, Martin CJ, Colonna M. The natural cytotoxicity receptors in health and disease. Front Immunol. (2019) 10:909. doi: 10.3389/fimmu.2019.00909

27. Campbell KS, Yusa S, Kikuchi-Maki A, Catina TL. NKp44 triggers NK cell activation through DAP12 association that is not influenced by a putative cytoplasmic inhibitory sequence. J Immunol. (2004) 172:899906. doi: 10.4049/jimmunol.172.2.899

28. Pazina T, Shemesh A, Brusilovsky M, Porgador A, Campbell KS. Regulation of the functions of natural cytotoxicity receptors by interactions with diverse ligands and alterations in splice variant expression. Front Immunol. (2017) 8:369. doi: 10.3389/fimmu.2017.00369

29. Brandt CS, Baratin M, Yi EC, Kennedy J, Gao Z, Fox B, et al. The B7 family member B7-H6 is a tumor cell ligand for the activating natural killer cell receptor NKp30 in humans. J Exp Med. (2009) 206:1495503. doi: 10.1084/jem.20090681 
30. Pogge von Strandmann E, Simhadri VR, von Tresckow B, Sasse S, Reiners KS, Hansen HP, et al. Human leukocyte antigen-B-associated transcript 3 is released from tumor cells and engages the NKp30 receptor on natural killer cells. Immunity. (2007) 27:965-74. doi: 10.1016/j.immuni.2007.10.010

31. Wang W, Guo H, Geng J, Zheng X, Wei H, Sun R, et al. Tumor-released Galectin-3, a soluble inhibitory ligand of human NKp30, plays an important role in tumor escape from NK cell attack. J Biol Chem. (2014) 289:333119. doi: 10.1074/jbc.M114.603464

32. Rosental B, Brusilovsky M, Hadad U, Oz D, Appel MY, Afergan F, et al. Proliferating cell nuclear antigen is a novel inhibitory ligand for the natural cytotoxicity receptor NKp44. J Immunol. (2011) 187:5693702. doi: 10.4049/jimmunol.1102267

33. Niehrs A, Garcia-Beltran WF, Norman PJ, Watson GM, Holzemer A, Chapel A, et al. A subset of HLA-DP molecules serve as ligands for the natural cytotoxicity receptor NKp44. Nat Immunol. (2019) 20:112937. doi: 10.1038/s41590-019-0448-4

34. Barrow AD, Edeling MA, Trifonov V, Luo J, Goyal P, Bohl B, et al. Natural killer cells control tumor growth by sensing a growth factor. Cell. (2018) 172:534-48 e19. doi: 10.1016/j.cell.2017.11.037

35. Gaggero S, Bruschi M, Petretto A, Parodi M, Del Zotto G, Lavarello C, et al. Nidogen-1 is a novel extracellular ligand for the NKp44 activating receptor. Oncoimmunology. (2018) 7:e1470730. doi: 10.1080/2162402X.2018.1470730

36. Groh V, Rhinehart R, Secrist H, Bauer S, Grabstein KH, Spies T. Broad tumor-associated expression and recognition by tumor-derived gamma delta T cells of MICA and MICB. Proc Natl Acad Sci USA. (1999) 96:687984. doi: 10.1073/pnas.96.12.6879

37. Pende D, Cantoni C, Rivera P, Vitale M, Castriconi R, Marcenaro S, et al. Role of NKG2D in tumor cell lysis mediated by human NK cells: cooperation with natural cytotoxicity receptors and capability of recognizing tumors of nonepithelial origin. Eur J Immunol. (2001) 31:1076-86. doi: 10.1002/15214141(200104)31:4<1076::AID-IMMU1076>3.3.CO;2-P

38. Jinushi M, Takehara T, Tatsumi T, Kanto T, Groh V, Spies T, et al. Expression and role of MICA and MICB in human hepatocellular carcinomas and their regulation by retinoic acid. Int J Cancer. (2003) 104:35461. doi: 10.1002/ijc. 10966

39. Salih HR, Antropius H, Gieseke F, Lutz SZ, Kanz L, Rammensee HG, et al. Functional expression and release of ligands for the activating immunoreceptor NKG2D in leukemia. Blood. (2003) 102:1389-96. doi: 10.1182/blood-2003-01-0019

40. Friese MA, Platten M, Lutz SZ, Naumann U, Aulwurm S, Bischof F, et al. MICA/NKG2D-mediated immunogene therapy of experimental gliomas. Cancer Res. (2003) 63:8996-9006.

41. Textor S, Bossler F, Henrich KO, Gartlgruber M, Pollmann J, Fiegler $\mathrm{N}$, et al. The proto-oncogene Myc drives expression of the NK cellactivating NKp30 ligand B7-H6 in tumor cells. Oncoimmunology. (2016) 5:e1116674. doi: 10.1080/2162402X.2015.1116674

42. Pende D, Spaggiari GM, Marcenaro S, Martini S, Rivera P, Capobianco A, et al. Analysis of the receptor-ligand interactions in the natural killermediated lysis of freshly isolated myeloid or lymphoblastic leukemias: evidence for the involvement of the Poliovirus receptor (CD155) and Nectin-2 (CD112). Blood. (2005) 105:2066-73. doi: 10.1182/blood-200409-3548

43. Carlsten M, Bjorkstrom NK, Norell H, Bryceson Y, van Hall T, Baumann $\mathrm{BC}$, et al. DNAX accessory molecule-1 mediated recognition of freshly isolated ovarian carcinoma by resting natural killer cells. Cancer Res. (2007) 67:1317-25. doi: 10.1158/0008-5472.CAN-06-2264

44. El-Sherbiny YM, Meade JL, Holmes TD, McGonagle D, Mackie SL, Morgan AW, et al. The requirement for DNAM-1, NKG2D, and NKp46 in the natural killer cell-mediated killing of myeloma cells. Cancer Res. (2007) 67:8444-9. doi: 10.1158/0008-5472.CAN-06-4230

45. Cerboni C, Fionda C, Soriani A, Zingoni A, Doria M, Cippitelli M, et al. The DNA damage response: a common pathway in the regulation of NKG2D and DNAM-1 ligand expression in normal, infected, and cancer cells. Front Immunol. (2014) 4:508. doi: 10.3389/fimmu.2013.00508

46. Doubrovina ES, Doubrovin MM, Vider E, Sisson RB, O’Reilly RJ, Dupont B, et al. Evasion from NK cell immunity by MHC class I chain-related molecules expressing colon adenocarcinoma. J Immunol. (2003) 171:68919. doi: 10.4049/jimmunol.171.12.6891
47. Rebmann V, Schutt P, Brandhorst D, Opalka B, Moritz T, Nowrousian MR, et al. Soluble MICA as an independent prognostic factor for the overall survival and progression-free survival of multiple myeloma patients. Clin Immunol. (2007) 123:114-20. doi: 10.1016/j.clim.2006.11.007

48. Jinushi M, Vanneman M, Munshi NC, Tai YT, Prabhala RH, Ritz J, et al. MHC class I chain-related protein A antibodies and shedding are associated with the progression of multiple myeloma. Proc Natl Acad Sci USA. (2008) 105:1285-90. doi: 10.1073/pnas.0711293105

49. Wu JD, Higgins LM, Steinle A, Cosman D, Haugk K, Plymate SR. Prevalent expression of the immunostimulatory MHC class I chain-related molecule is counteracted by shedding in prostate cancer. J Clin Invest. (2004) 114:5608. doi: 10.1172/JCI200422206

50. Holdenrieder S, Stieber P, Peterfi A, Nagel D, Steinle A, Salih HR. Soluble MICB in malignant diseases: analysis of diagnostic significance and correlation with soluble MICA. Cancer Immunol Immunother. (2006) 55:1584-9. doi: 10.1007/s00262-006-0167-1

51. Holdenrieder S, Stieber P, Peterfi A, Nagel D, Steinle A, Salih HR. Soluble MICA in malignant diseases. Int J Cancer. (2006) 118:6847. doi: $10.1002 /$ ijc. 21382

52. Baragano Raneros A, Suarez-Alvarez B, Lopez-Larrea C. Secretory pathways generating immunosuppressive NKG2D ligands: New targets for therapeutic intervention. Oncoimmunology. (2014) 3:e28497. doi: 10.4161/onci.28497

53. Paschen A, Sucker A, Hill B, Moll I, Zapatka M, Nguyen XD, et al. Differential clinical significance of individual NKG2D ligands in melanoma: soluble ULBP2 as an indicator of poor prognosis superior to S100B. Clin Cancer Res. (2009) 15:5208-15. doi: 10.1158/1078-0432.CCR-09-0886

54. Iguchi-Manaka A, Okumura G, Kojima H, Cho Y, Hirochika R, Bando H, et al. Increased soluble CD155 in the serum of cancer patients. PLoS ONE. (2016) 11:e0152982. doi: 10.1371/journal.pone.0152982

55. Semeraro M, Rusakiewicz S, Minard-Colin V, Delahaye NF, Enot D, Vely F, et al. Clinical impact of the NKp30/B7-H6 axis in high-risk neuroblastoma patients. Sci Trans Med. (2015) 7:283ra55. doi: 10.1126/scitranslmed.aaa2327

56. Pesce S, Tabellini G, Cantoni C, Patrizi O, Coltrini D, Rampinelli F, et al. B7-H6-mediated downregulation of NKp30 in NK cells contributes to ovarian carcinoma immune escape. Oncoimmunology. (2015) 4:e1001224. doi: 10.1080/2162402X.2014.1001224

57. Schlecker E, Fiegler N, Arnold A, Altevogt P, Rose-John S, Moldenhauer G, et al. Metalloprotease-mediated tumor cell shedding of B7-H6, the ligand of the natural killer cell-activating receptor NKp30. Cancer Res. (2014) 74:3429-40. doi: 10.1158/0008-5472.CAN-13-3017

58. Rusakiewicz S, Perier A, Semeraro M, Pitt JM, Pogge von Strandmann E, Reiners KS, et al. NKp30 isoforms and NKp30 ligands are predictive biomarkers of response to imatinib mesylate in metastatic GIST patients. Oncoimmunology. (2017) 6:e1137418. doi: 10.1080/2162402X.2015.1137418

59. Baury B, Masson D, McDermott BM Jr, Jarry A, Blottiere HM, Blanchardie $\mathrm{P}$, et al. Identification of secreted CD155 isoforms. Biochem Biophys Res Commun. (2003) 309:175-82. doi: 10.1016/S0006-291X(03)01560-2

60. Bacon L, Eagle RA, Meyer M, Easom N, Young NT, Trowsdale J. Two human ULBP/RAET1 molecules with transmembrane regions are ligands for NKG2D. J Immunol. (2004) 173:1078-84. doi: 10.4049/jimmunol.173.2.1078

61. Cao W, Xi X, Hao Z, Li W, Kong Y, Cui L, et al. RAET1E2, a soluble isoform of the UL16-binding protein RAET1E produced by tumor cells, inhibits NKG2D-mediated NK cytotoxicity. J Biol Chem. (2007) 282:189228. doi: 10.1074/jbc.M702504200

62. Mathieu M, Martin-Jaular L, Lavieu G, Thery C. Specificities of secretion and uptake of exosomes and other extracellular vesicles for cell-to-cell communication. Nat Cell Biol. (2019) 21:9-17. doi: 10.1038/s41556-018-0250-9

63. Labani-Motlagh A, Israelsson P, Ottander U, Lundin E, Nagaev I, Nagaeva O, et al. Differential expression of ligands for NKG2D and DNAM-1 receptors by epithelial ovarian cancer-derived exosomes and its influence on NK cell cytotoxicity. Tumour Biol. (2016) 37:545566. doi: 10.1007/s13277-015-4313-2

64. Lopez-Cobo S, Campos-Silva C, Moyano A, Oliveira-Rodriguez M, Paschen A, Yanez-Mo M, et al. Immunoassays for scarce tumourantigens in exosomes: detection of the human NKG2D-Ligand, MICA, in tetraspanin-containing nanovesicles from melanoma. J Nanobiotechnol. (2018) 16:47. doi: 10.1186/s12951-018-0372-z 
65. Lundholm M, Schroder M, Nagaeva O, Baranov V, Widmark A, MinchevaNilsson L, et al. Prostate tumor-derived exosomes down-regulate NKG2D expression on natural killer cells and CD8+ T cells: mechanism of immune evasion. PLoS ONE. (2014) 9:e108925. doi: 10.1371/journal.pone.0108925

66. Fernandez-Messina L, Ashiru O, Boutet P, Aguera-Gonzalez S, Skepper JN, Reyburn HT, et al. Differential mechanisms of shedding of the glycosylphosphatidylinositol (GPI)-anchored NKG2D ligands. J Biol Chem. (2010) 285:8543-51. doi: 10.1074/jbc.M109.045906

67. Ashiru O, Boutet P, Fernandez-Messina L, Aguera-Gonzalez S, Skepper JN, Vales-Gomez M, et al. Natural killer cell cytotoxicity is suppressed by exposure to the human NKG2D ligand MICA*008 that is shed by tumor cells in exosomes. Cancer Res. (2010) 70:481-9. doi: 10.1158/0008-5472.CAN-09-1688

68. Ashiru O, Lopez-Cobo S, Fernandez-Messina L, Pontes-Quero S, Pandolfi R, Reyburn HT, et al. A GPI anchor explains the unique biological features of the common NKG2D-ligand allele MICA*008. Biochem J. (2013) 454:295302. doi: 10.1042/BJ20130194

69. Dassler-Plenker J, Reiners KS, van den Boorn JG, Hansen HP, Putschli B, Barnert S, et al. RIG-I activation induces the release of extracellular vesicles with antitumor activity. Oncoimmunology. (2016) 5:e1219827. doi: 10.1080/2162402X.2016.1219827

70. Gutierrez-Franco J, Hernandez-Gutierrez R, Bueno-Topete MR, Haramati J, Navarro-Hernandez RE, Escarra-Senmarti $M$, et al. Characterization of B7H6, an endogenous ligand for the $\mathrm{NK}$ cell activating receptor NKp30, reveals the identity of two different soluble isoforms during normal human pregnancy. Immunobiology. (2018) 223:57-63. doi: 10.1016/j.imbio.2017.10.012

71. Matta J, Baratin M, Chiche L, Forel JM, Cognet C, Thomas G, et al. Induction of B7-H6, a ligand for the natural killer cell-activating receptor NKp30, in inflammatory conditions. Blood. (2013) 122:394404. doi: 10.1182/blood-2013-01-481705

72. Vulpis E, Cecere F, Molfetta R, Soriani A, Fionda C, Peruzzi G, et al. Genotoxic stress modulates the release of exosomes from multiple myeloma cells capable of activating NK cell cytokine production: role of HSP70/TLR2/NF-kB axis. Oncoimmunology. (2017) 6:e1279372. doi: 10.1080/2162402X.2017.1279372

73. Gobbo J, Marcion G, Cordonnier M, Dias AMM, Pernet N, Hammann A, et al. Restoring Anticancer immune response by targeting tumor-derived exosomes with a HSP70 peptide aptamer. J Natl Cancer Inst. (2016) 108:1-11. doi: $10.1093 /$ jnci/djv330

74. Hedlund M, Nagaeva O, Kargl D, Baranov V, Mincheva-Nilsson L. Thermaland oxidative stress causes enhanced release of NKG2D ligand-bearing immunosuppressive exosomes in leukemia/lymphoma T and B cells. PLoS ONE. (2011) 6:e16899. doi: 10.1371/journal.pone.0016899

75. Vulpis E, Soriani A, Cerboni C, Santoni A, Zingoni A. Cancer exosomes as conveyors of stress-induced molecules: new players in the modulation of NK cell response. Int J Mol Sci. (2019) 20:E611. doi: 10.3390/ijms20030611

76. Waldhauer I, Steinle A. Proteolytic release of soluble UL16binding protein 2 from tumor cells. Cancer Res. (2006) 66:2520-6. doi: 10.1158/0008-5472.CAN-05-2520

77. Waldhauer I, Goehlsdorf D, Gieseke F, Weinschenk T, Wittenbrink M, Ludwig A, et al. Tumor-associated MICA is shed by ADAM proteases. Cancer Res. (2008) 68:6368-76. doi: 10.1158/0008-5472.CAN-07-6768

78. Boutet P, Aguera-Gonzalez S, Atkinson S, Pennington CJ, Edwards DR, Murphy G, et al. Cutting edge: the metalloproteinase ADAM17/TNF-alpha-converting enzyme regulates proteolytic shedding of the MHC class I-related chain B protein. J Immunol. (2009) 182:49-53. doi: 10.4049/jimmunol.182.1.49

79. Liu G, Atteridge CL, Wang X, Lundgren AD, Wu JD. The membrane type matrix metalloproteinase MMP14 mediates constitutive shedding of MHC class I chain-related molecule A independent of A disintegrin and metalloproteinases. J Immunol. (2010) 184:3346-50. doi: 10.4049/jimmunol.0903789

80. Chitadze G, Lettau M, Bhat J, Wesch D, Steinle A, Furst D, et al. Shedding of endogenous MHC class I-related chain molecules A and B from different human tumor entities: heterogeneous involvement of the "a disintegrin and metalloproteases" 10 and 17. Int J Cancer. (2013) 133:155766. doi: $10.1002 /$ ijc. 28174
81. Chitadze G, Bhat J, Lettau M, Janssen O, Kabelitz D. Generation of soluble NKG2D ligands: proteolytic cleavage, exosome secretion and functional implications. Scand J Immunol. (2013) 78:120-9. doi: 10.1111/sji.12072

82. Zoller T, Wittenbrink M, Hoffmeister M, Steinle A. Cutting an NKG2D ligand short: cellular processing of the peculiar human NKG2D ligand ULBP4. Front Immunol. (2018) 9:620. doi: 10.3389/fimmu.2018.00620

83. Winer A, Adams S, Mignatti P. Matrix metalloproteinase inhibitors in cancer therapy: turning past failures into future successes. Mol Cancer Ther. (2018) 17:1147-55. doi: 10.1158/1535-7163.MCT-17-0646

84. Mochizuki S, Okada Y. ADAMs in cancer cell proliferation and progression. Cancer Sci. (2007) 98:621-8. doi: 10.1111/j.1349-7006.2007.00434.x

85. Siemens DR, Hu N, Sheikhi AK, Chung E, Frederiksen LJ, Pross H, et al. Hypoxia increases tumor cell shedding of MHC class I chainrelated molecule: role of nitric oxide. Cancer Res. (2008) 68:474653. doi: 10.1158/0008-5472.CAN-08-0054

86. Barsoum IB, Hamilton TK, Li X, Cotechini T, Miles EA, Siemens DR, et al. Hypoxia induces escape from innate immunity in cancer cells via increased expression of ADAM10: role of nitric oxide. Cancer Res. (2011) 71:7433-41. doi: 10.1158/0008-5472.CAN-11-2104

87. Heo W, Lee YS, Son CH, Yang K, Park YS, Bae J. Radiation-induced matrix metalloproteinases limit natural killer cell-mediated anticancer immunity in NCI-H23 lung cancer cells. Mol Med Rep. (2015) 11:18006. doi: 10.3892/mmr.2014.2918

88. Zingoni A, Vulpis E, Nardone I, Soriani A, Fionda C, Cippitelli M, et al. Targeting NKG2D and NKp30 ligands shedding to improve NK cell-based immunotherapy. Crit Rev Immunol. (2016) 36:44560. doi: 10.1615/CritRevImmunol.2017020166

89. Isernhagen A, Schilling D, Monecke S, Shah P, Elsner L, Walter L, et al. The MICA-129Met/Val dimorphism affects plasma membrane expression and shedding of the NKG2D ligand MICA. Immunogenetics. (2016) 68:10923. doi: $10.1007 / \mathrm{s} 00251-015-0884-8$

90. Zingoni A, Vulpis E, Cecere F, Amendola MG, Fuerst D, Saribekyan $\mathrm{T}$, et al. MICA-129 dimorphism and soluble MICA are associated with the progression of multiple myeloma. Front Immunol. (2018) 9:926. doi: 10.3389/fimmu.2018.00926

91. Aguera-Gonzalez S, Gross CC, Fernandez-Messina L, Ashiru O, Esteso G, Hang HC, et al. Palmitoylation of MICA, a ligand for NKG2D, mediates its recruitment to membrane microdomains and promotes its shedding. Eur J Immunol. (2011) 41:3667-76. doi: 10.1002/eji.201141645

92. Komander D, Rape M. The ubiquitin code. Annu Rev Biochem. (2012) 81:203-29. doi: 10.1146/annurev-biochem-060310-170328

93. Bettermann K, Benesch $\mathrm{M}$, Weis $\mathrm{S}$, Haybaeck J. SUMOylation in carcinogenesis. Cancer Lett. (2012) 316:11325. doi: 10.1016/j.canlet.2011.10.036

94. Flotho A, Melchior F. Sumoylation: a regulatory protein modification in health and disease. Annu Rev Biochem. (2013) 82:357-85. doi: 10.1146/annurev-biochem-061909-093311

95. Varshavsky A. The ubiquitin system, autophagy, and regulated protein degradation. Annu Rev Biochem. (2017) 86:12328. doi: 10.1146/annurev-biochem-061516-044859

96. Molfetta R, Gasparrini F, Santoni A, Paolini R. Ubiquitination and endocytosis of the high affinity receptor for IgE. Mol Immunol. (2010) 47:2427-34. doi: 10.1016/j.molimm.2010.06.003

97. Thomas M, Boname JM, Field S, Nejentsev S, Salio M, Cerundolo V, et al. Down-regulation of NKG2D and NKp80 ligands by Kaposi's sarcomaassociated herpesvirus $\mathrm{K} 5$ protects against NK cell cytotoxicity. Proc Nat Acad Sci USA. (2008) 105:1656-61. doi: 10.1073/pnas.0707883105

98. Nice TJ, Coscoy L, Raulet DH. Posttranslational regulation of the NKG2D ligand Mult1 in response to cell stress. J Exp Med. (2009) 206:28798. doi: 10.1084/jem.20081335

99. Nice TJ, Deng W, Coscoy L, Raulet DH. Stress-regulated targeting of the NKG2D ligand Mult1 by a membrane-associated RING-CH family E3 ligase. J Immunol. (2010) 185:5369-76. doi: 10.4049/jimmunol.1000247

100. Fuertes MB, Girart MV, Molinero LL, Domaica CI, Rossi LE, Barrio $\mathrm{MM}$, et al. Intracellular retention of the NKG2D ligand MHC class I chain-related gene $\mathrm{A}$ in human melanomas confers immune privilege and prevents NK cell-mediated cytotoxicity. J Immunol. (2008) 180:460614. doi: 10.4049/jimmunol.180.7.4606 
101. Aguera-Gonzalez S, Boutet P, Reyburn HT, Vales-Gomez M. Brief residence at the plasma membrane of the MHC class I-related chain B is due to clathrin-mediated cholesterol-dependent endocytosis and shedding. $J$ Immunol. (2009) 182:4800-8. doi: 10.4049/jimmunol.0800713

102. Bilotta MT, Abruzzese MP, Molfetta R, Scarno G, Fionda C, Zingoni A, et al. Activation of liver $X$ receptor up-regulates the expression of the NKG2D ligands MICA and MICB in multiple myeloma through different molecular mechanisms. FASEB J. (2019) 33:9489-504. doi: 10.1096/fj.201900319R

103. Fernandez-Messina L, Reyburn HT, Vales-Gomez M. A short half-life of ULBP1 at the cell surface due to internalization and proteosomal degradation. Immunol Cell Biol. (2016) 94:479-85. doi: 10.1038/icb.2016.2

104. Gong J, Fang L, Liu R, Wang Y, Xing J, Chen Y, et al. UPR decreases CD226 ligand CD155 expression and sensitivity to NK cellmediated cytotoxicity in hepatoma cells. Eur J Immunol. (2014) 44:375867. doi: 10.1002/eji.201444574

105. Zitti B, Molfetta R, Fionda C, Quatrini L, Stabile H, Lecce M, et al. Innate immune activating ligand SUMOylation affects tumor cell recognition by NK cells. Sci Rep. (2017) 7:10445. doi: 10.1038/s41598-017-10403-0

106. Molfetta R, Milito ND, Zitti B, Lecce M, Fionda C, Cippitelli M, et al. The Ubiquitin-proteasome pathway regulates Nectin2/CD112 expression and impairs NK cell recognition and killing. Eur J Immunol. (2019) 49:87383. doi: 10.1002/eji.201847848

107. Costello RT, Sivori S, Marcenaro E, Lafage-Pochitaloff M, Mozziconacci MJ, Reviron D, et al. Defective expression and function of natural killer celltriggering receptors in patients with acute myeloid leukemia. Blood. (2002) 99:3661-7. doi: 10.1182/blood.V99.10.3661

108. Garcia-Iglesias T, Del Toro-Arreola A, Albarran-Somoza B, Del ToroArreola S, Sanchez-Hernandez PE, Ramirez-Duenas MG, et al. Low NKp30, NKp46 and NKG2D expression and reduced cytotoxic activity on NK cells in cervical cancer and precursor lesions. BMC Cancer. (2009) 9:186. doi: 10.1186/1471-2407-9-186

109. Charrier M, Mezquita L, Lueza B, Dupraz L, Planchard D, Remon J, et al. Circulating innate immune markers and outcomes in treatmentnaive advanced non-small cell lung cancer patients. Eur J Cancer. (2019) 108:88-96. doi: 10.1016/j.ejca.2018.12.017

110. Carlsten M, Norell H, Bryceson YT, Poschke I, Schedvins K, Ljunggren HG, et al. Primary human tumor cells expressing CD155 impair tumor targeting by down-regulating DNAM-1 on NK cells. J Immunol. (2009) 183:4921-30. doi: 10.4049/jimmunol.0901226

111. Sanchez-Correa B, Gayoso I, Bergua JM, Casado JG, Morgado S, Solana R, et al. Decreased expression of DNAM-1 on NK cells from acute myeloid leukemia patients. Immunol Cell Biol. (2012) 90:10915. doi: 10.1038/icb.2011.15

112. Groh V, Wu J, Yee C, Spies T. Tumour-derived soluble MIC ligands impair expression of NKG2D and T-cell activation. Nature. (2002) 419:7348. doi: $10.1038 /$ nature 01112

113. Oppenheim DE, Roberts SJ, Clarke SL, Filler R, Lewis JM, Tigelaar RE, et al. Sustained localized expression of ligand for the activating NKG2D receptor impairs natural cytotoxicity in vivo and reduces tumor immunosurveillance. Nat Immunol. (2005) 6:928-37. doi: 10.1038/ni1239

114. Molfetta R, Quatrini L, Capuano C, Gasparrini F, Zitti B, Zingoni A, et al. c-Cbl regulates MICA- but not ULBP2-induced NKG2D downmodulation in human NK cells. Eur J Immunol. (2014) 44:276170. doi: 10.1002/eji.201444512

115. Molfetta R, Quatrini L, Zitti B, Capuano C, Galandrini R, Santoni A, et al. Regulation of NKG2D expression and signaling by endocytosis. Trends Immunol. (2016) 37:790-802. doi: 10.1016/j.it.2016.08.015

116. Quatrini L, Molfetta R, Zitti B, Peruzzi G, Fionda C, Capuano C, et al. Ubiquitin-dependent endocytosis of NKG2D-DAP10 receptor complexes activates signaling and functions in human NK cells. Sci Signal. (2015) 8:ra108. doi: 10.1126/scisignal.aab2724

117. Paolini R, Serra A, Molfetta R, Piccoli M, Frati L, Santoni A. Tyrosine kinase-dependent ubiquitination of CD16 zeta subunit in human NK cells following receptor engagement. Eur J Immunol. (1999) 29:317987. doi: 10.1002/(SICI)1521-4141(199910)29:10<3179::AID-IMMU $3179>3.0 . \mathrm{CO} ; 2-9$

118. Capuano C, Romanelli M, Pighi C, Cimino G, Rago A, Molfetta $\mathrm{R}$, et al. Anti-CD20 therapy acts via FcgammaRIIIA to diminish responsiveness of human natural killer cells. Cancer Res. (2015) 75:4097108. doi: 10.1158/0008-5472.CAN-15-0781

119. Capuano C, Pighi C, Molfetta R, Paolini R, Battella S, Palmieri G, et al. Obinutuzumab-mediated high-affinity ligation of FcgammaRIIIA/CD16 primes NK cells for IFNgamma production. Oncoimmunology. (2017) 6:e1290037. doi: 10.1080/2162402X.2017.1290037

120. Paolini R, Molfetta R, Piccoli M, Frati L, Santoni A. Ubiquitination and degradation of Syk and ZAP-70 protein tyrosine kinases in human NK cells upon CD16 engagement. Proc Natl Acad Sci USA. (2001) 98:96116. doi: 10.1073/pnas.161298098

121. Borrego F, Lopez-Beltran A, Pena J, Solana R. Downregulation of Fc gamma receptor IIIA alpha (CD16-II) on natural killer cells induced by anti-CD16 $\mathrm{mAb}$ is independent of protein tyrosine kinases and protein kinase C. Cell Immunol. (1994) 158:208-17. doi: 10.1006/cimm.1994.1268

122. Grzywacz B, Kataria N, Verneris MR. CD56(dim)CD16(+) NK cells downregulate CD16 following target cell induced activation of matrix metalloproteinases. Leukemia. (2007) 21:356-9. doi: 10.1038/sj.leu.2404499

123. Romee R, Foley B, Lenvik T, Wang Y, Zhang B, Ankarlo D, et al. NK cell CD16 surface expression and function is regulated by a disintegrin and metalloprotease-17 (ADAM17). Blood. (2013) 121:3599608. doi: 10.1182/blood-2012-04-425397

124. Peruzzi G, Femnou L, Gil-Krzewska A, Borrego F, Weck J, Krzewski K, et al. Membrane-type 6 matrix metalloproteinase regulates the activation-induced downmodulation of CD16 in human primary NK cells. J Immunol. (2013) 191:1883-94. doi: 10.4049/jimmunol.1300313

125. Zhou Q, Gil-Krzewska A, Peruzzi G, Borrego F. Matrix metalloproteinases inhibition promotes the polyfunctionality of human natural killer cells in therapeutic antibody-based anti-tumour immunotherapy. Clin Exp Immunol. (2013) 173:131-9. doi: 10.1111/cei.12095

126. Waldhauer I, Steinle A. NK cells and cancer immunosurveillance. Oncogene. (2008) 27:5932-43. doi: 10.1038/onc.2008.267

127. Zingoni A, Cecere F, Vulpis E, Fionda C, Molfetta R, Soriani A, et al. Genotoxic stress induces senescence-associated ADAM10-dependent release of NKG2D MIC ligands in multiple myeloma cells. J Immunol. (2015) 195:736-48. doi: 10.4049/jimmunol.1402643

128. Arai J, Goto K, Tanoue Y, Ito S, Muroyama R, Matsubara Y, et al. Enzymatic inhibition of MICA sheddase ADAM17 by lomofungin in hepatocellular carcinoma cells. Int J Cancer. (2018) 143:2575-83. doi: 10.1002/ijc.31615

129. Mullooly M, McGowan PM, Crown J, Duffy MJ. The ADAMs family of proteases as targets for the treatment of cancer. Cancer Biol Ther. (2016) 17:870-80. doi: 10.1080/15384047.2016.1177684

130. Camodeca C, Nuti E, Tepshi L, Boero S, Tuccinardi T, Stura EA, et al. Discovery of a new selective inhibitor of A Disintegrin And Metalloprotease 10 (ADAM-10) able to reduce the shedding of NKG2D ligands in Hodgkin's lymphoma cell models. Eur J Med Chem. (2016) 111:193201. doi: 10.1016/j.ejmech.2016.01.053

131. Wolpert F, Tritschler I, Steinle A, Weller M, Eisele G. A disintegrin and metalloproteinases 10 and 17 modulate the immunogenicity of glioblastomainitiating cells. Neuro Oncol. (2014) 16:382-91. doi: 10.1093/neuonc/not232

132. Huang B, Sikorski R, Sampath P, Thorne SH. Modulation of NKG2Dligand cell surface expression enhances immune cell therapy of cancer. $J$ Immunother. (2011) 34:289-96. doi: 10.1097/CJI.0b013e31820e1b0d

133. Kloess S, Huenecke S, Piechulek D, Esser R, Koch J, Brehm C, et al. IL-2-activated haploidentical NK cells restore NKG2D-mediated NK-cell cytotoxicity in neuroblastoma patients by scavenging of plasma MICA. Eur J Immunol. (2010) 40:3255-67. doi: 10.1002/eji.201040568

134. Ferrari de Andrade L, Tay RE, Pan D, Luoma AM, Ito Y, Badrinath $S$, et al. Antibody-mediated inhibition of MICA and MICB shedding promotes NK cell-driven tumor immunity. Science. (2018) 359:153742. doi: 10.1126/science.aao0505

135. Lombana TN, Matsumoto ML, Berkley AM, Toy E, Cook R, Gan Y, et al. High-resolution glycosylation site-engineering method identifies MICA epitope critical for shedding inhibition activity of anti-MICA antibodies. mAbs. (2019) 11:75-93. doi: 10.1080/19420862.2018.1532767

136. Mishra HK, Pore N, Michelotti EF, Walcheck B. Anti-ADAM17 monoclonal antibody MEDI3622 increases IFNgamma production by human NK cells in the presence of antibody-bound tumor cells. Cancer Immunol Immunother. (2018) 67:1407-16. doi: 10.1007/s00262-018-2193-1 
137. Chen D, Frezza M, Schmitt S, Kanwar J, Dou QP. Bortezomib as the first proteasome inhibitor anticancer drug: current status and future perspectives. Curr Cancer Drug Targets. (2011) 11:239-53. doi: 10.2174/1568009117945 19752

138. Kisselev AF, van der Linden WA, Overkleeft HS. Proteasome inhibitors: an expanding army attacking a unique target. Chem Biol. (2012) 19:99115. doi: 10.1016/j.chembiol.2012.01.003

139. Vandross A. Proteasome inhibitor-based therapy for treatment of newly diagnosed multiple myeloma. Semin Oncol. (2017) 44:381-84. doi: 10.1053/j.seminoncol.2018.01.002

140. Morrow JK, Lin HK, Sun SC, Zhang S. Targeting ubiquitination for cancer therapies. Future Med Chem. (2015) 7:2333-50. doi: 10.4155/fmc.15.148

141. Niu C, Jin $\mathrm{H}$, Li M, Zhu S, Zhou L, Jin F, et al. Low-dose bortezomib increases the expression of NKG2D and DNAM-1 ligands and enhances induced $\mathrm{NK}$ and gammadelta $\mathrm{T}$ cell-mediated lysis in multiple myeloma. Oncotarget. (2017) 8:5954-64. doi: 10.18632/oncotarget. 13979

142. Soriani A, Zingoni A, Cerboni C, Iannitto ML, Ricciardi MR, Di Gialleonardo V, et al. ATM-ATR-dependent up-regulation of DNAM-1 and NKG2D ligands on multiple myeloma cells by therapeutic agents results in enhanced NK-cell susceptibility and is associated with a senescent phenotype. Blood. (2009) 113:3503-11. doi: 10.1182/blood-2008-08-1 73914

143. Fionda C, Stabile H, Molfetta R, Soriani A, Bernardini G, Zingoni A, et al. Translating the anti-myeloma activity of Natural Killer cells into clinical application. Cancer Treat Rev. (2018) 70:255-64. doi: 10.1016/j.ctrv.2018.10.005
144. Bernstock JD, Ye D, Gessler FA, Lee YJ, Peruzzotti-Jametti L, Baumgarten $\mathrm{P}$, et al. Topotecan is a potent inhibitor of SUMOylation in glioblastoma multiforme and alters both cellular replication and metabolic programming. Sci Rep. (2017) 7:7425. doi: 10.1038/s41598-017-07631-9

145. Fukuda I, Ito A, Hirai G, Nishimura S, Kawasaki H, Saitoh $H$, et al. Ginkgolic acid inhibits protein SUMOylation by blocking formation of the E1-SUMO intermediate. Chem Biol. (2009) 16:133-40. doi: 10.1016/j.chembiol.2009.01.009

146. Suzawa M, Miranda DA, Ramos KA, Ang KK, Faivre EJ, Wilson $\mathrm{CG}$, et al. A gene-expression screen identifies a non-toxic sumoylation inhibitor that mimics SUMO-less human LRH-1 in liver. eLife. (2015) 4:e09003. doi: 10.7554/eLife.09003

147. Yang Y, Xia Z, Wang X, Zhao X, Sheng Z, Ye Y, et al. Small-molecule inhibitors targeting protein SUMOylation as novel anticancer compounds. Mol Pharmacol. (2018) 94:885-94. doi: 10.1124/mol.118.112300

Conflict of Interest: The authors declare that the research was conducted in the absence of any commercial or financial relationships that could be construed as a potential conflict of interest.

Copyright $\odot 2019$ Molfetta, Zingoni, Santoni and Paolini. This is an open-access article distributed under the terms of the Creative Commons Attribution License (CC $B Y)$. The use, distribution or reproduction in other forums is permitted, provided the original author(s) and the copyright owner(s) are credited and that the original publication in this journal is cited, in accordance with accepted academic practice. No use, distribution or reproduction is permitted which does not comply with these terms. 